\title{
Building a digital economy (the case of BRICS)
}

\author{
Svetlana Gusarova ${ }^{1, *}$, Igor Gusarov ${ }^{1}$, and Margarita Smeretchinskii ${ }^{2}$ \\ ${ }^{1}$ Plekhanov Russian University of Economics, 117997 Moscow, Russia \\ ${ }^{2}$ York University, Schulich School of Business, 4700 Toronto, Canada
}

\begin{abstract}
The main direction of our research on building a digital economy includes the introduction of blockchain and cryptocurrency in the BRICS countries; advantages, obstacles, and prospects of the digital economy; the impact of robotization on the economic development of countries. The digital transformation of the economy of the BRICS group can be facilitated by the use of blockchain technology. The study identified the main advantages, threats and directions for the creation and use of a new cryptocurrency (BRICScoin) and blockchain technology by the BRICS countries. The digital economy is on the agenda around the world today, it is a new paradigm for the development of countries' cooperation, and can become a driver of their economic growth. On the basis of the analysis, the advantages, obstacles and recommendations for the development of digital transformation in the BRICS countries were identified. Research in the development of robotics has revealed the benefits and challenges of this process. The use of a mathematical model made it possible to conclude that the growth of an existing fleet of industrial robots in the country affects the growth of its economy. The further development of robotics in the country will help increase its economic potential, product quality and export of innovative high-tech products.
\end{abstract}

\section{Introduction}

Digital transformation of the economies will help BRICS countries to increase their GDP, especially while overcoming problems of COVID-19. Introduction of information technologies, transfer to the digital economy, development of e-commerce, and robotization are on the agenda all over the world today.

The development of the potential for economic cooperation of the BRICS group can be facilitated by the use of blockchain technology - a distributed database organization system, which is an innovative direction in the development of the financial mechanism in the global economy [1, P.80-84].

Blockchain is recognized by many countries that are studying the application of innovative technology in many areas, ensuring reliability and efficiency. It is predicted that by 2025 about $10 \%$ of global GDP will be stored using blockchain technology. By 2030, the use of blockchain technology in the global economy will increase the added value of goods and services to $\$ 3.1$ trillion [2].

1,242 companies are actively involved in the blockchain industry worldwide. The largest number of blockchain companies in the global economy are engaged in technologies and services

*Corresponding author: s-gusarova@mail.ru 
related to cryptocurrency (467 units, or $37.6 \%$ ), followed by technology blockchain companies, as well as companies engaged in research and development of a software platform (201 units, or $16.2 \%$ ). In third place are blockchain companies developing financial technologies (152 units, or $12 \%)[3]$.

Many countries are trying to implement blockchain in their economies. For example, work is underway to launch cross-border payments using blockchain technology in Singapore and India. In 2018, there were 18 blockchain companies operating in India. New blockchain accelerator introduced in Japan. In January 2018, the UK invested \$19 million to create innovative products or services in the blockchain. There are 97 blockchain companies operating in the UK, 455 blockchain companies - in the US (number one in the world), 15 blockchain companies operating in Korea, 15 blockchain companies - in Australia [3]. The BRICS countries are also working on the implementation of blockchain technology in banking systems and other spheres.

The development of digital transformation of the economy is a new paradigm of the development of international cooperation of the five states. This problem is important, but still insufficiently studied and not enough reflected in the economic research.

During the study, the authors hypothesized that R\&D funding affects the development of robotics and the economic development of the BRICS countries. To substantiate this hypothesis, an analysis of the development of robotics was carried out and its role in the development of their economies was determined. Thus, the authors were able to highlight the main advantages and problems of the development of robotics.

The rest of the article is structured as follows. Section 2 presents the materials and methods used in the study. Section 3 discusses the main directions of the development of digital transformation of the economies, as well as the results of the introduction of blockchain and cryptocurrency in BRICS countries. Finally, section 4 provides recommendations for the further development of digital transformation of the economies in the BRICS countries and proposals for future research.

\section{Materials and methods}

The theoretical basis of the study is the works of Russian, Western and Asian researchers on the problems of the formation and development of a digital economy in the BRICS countries. The methodological basis of the study is general scientific research methods: a historical and logical approach, an abstraction method, analysis and synthesis, situational analysis, models of correlation and regression analysis, statistical methods of comparative analysis, intercountry comparable and other methodology.

To determine the impact of R\&D funding on the development of robotics, and the impact of robotics on the development of the economy, authors carried out correlation and regression analysis. The regression coefficient was calculated as:

$$
Y=\beta_{1} \mathrm{x}_{1}+\beta_{0}
$$

where $\beta_{1}$ is the regression coefficient of the first-factor indicator $\left(\mathrm{X}_{1}\right) ; \beta_{o}$ is the free sign that determines the volume of GDP $(Y)$ in cases where the factor sign $\left(\mathrm{X}_{1}\right)$ equals 07

$$
\beta_{1}=S P / S S x
$$

SP is the sum of cross products between two derivatives ( $X_{1}$ and Y); SSx - sum of squares of deviations from the mean value $X_{1}$.

$$
S P=\sum\left(X_{1}-M X_{1}\right)(Y-M Y)
$$

$\left(M X_{1}\right)$ is the arithmetic mean of; MY is the arithmetic mean of $Y$.

$$
S S x=\sum\left(X_{1}-M X_{1}\right)^{2}
$$

When solving the regression equation, the least-squares method and the matrix method were used. 
Information and statistical research base of the study, which ensures the reliability of conclusions, recommendations and proposals, is the scientific research papers of scientists, actual analysis of economic processes submitted to leading scientific publications, collections of scientific conferences, regulatory and legal base, strategies and reports of BRICS countries, official statistics data, World Bank data, analytical reports of the World Economic Forum, the International Monetary Fund, World Trade Organization, Association for the Development of Financial Technologies, International Federation of Robotics, Institute for Development and Research in Banking Technology, Chinese Academy of Information and Communication Technology, Russian Association of Cryptocurrencies and Blockchain. The authors also used materials from periodicals, data from sites on the Internet.

\section{Discussion. Development of digital cooperation between the BRICS countries}

\subsection{Implementation of blockchain and cryptocurrency in BRICS countries}

Currently, the blockchain is still at the stage of a social experiment, there is no consensus on the concept, structure, technical specifications, development program, management and supervision of the blockchain system. This is one of the indispensable technologies for the development of the digital economy in the future. "As the underlying technology of bitcoin, blockchain is expected to create a new economic system by revolutionizing the way we communicate over the internet" [4].

In China, the Ministry of Industry and Information Technology published the Industrial Internet Development Plan (2018-2020). The plan aims to promote the application and research of modern computing, blockchain deep learning, and other advanced technologies on the industrial Internet. On May 28, 2018, Chairman Xi Jinping, speaking at the Congress of the Chinese Academy of Sciences, noted that a new generation of information technology represented by artificial intelligence, quantum information, mobile communications, the Internet of things and blockchain technology is accelerating breakthrough in economic development. And in 2019, Xi Jinping called on China to become a leader in the implementation of blockchain technology in various sectors of the economy. China "needs to devote great energy to promoting science and technology, and endeavor to be a major world center for science and innovation" [5].

In China, 24 provinces, cities or regions, including Beijing (43.2\% of Chinese blockchain companies operated), Shanghai (23.5\%), Shenzhen (13.8\%), Guangdong, Hebei (Xiongan), Jiangsu, Shandong, Guizhou, Gansu and Hainan have developed guidelines for the implementation of blockchain technology. Chinese Academy of Information and Communication Technology (affiliated with the Ministry of Industry and Information of China) established a Research Center. In 2018, the Research Center developed the "Blockchain White Paper" [3]. It interprets the concept and architecture of blockchain technology, analyzes the directions of development and the possibility of implementing blockchain in various sectors of the economy, reveals the problems associated with the use of blockchain technology, and offers recommendations for its development. Blockchain implementation contributes to building a digital economy and industrial ecology.

In 2018, there were 298 blockchain companies in China. In 2017, the Institute of Digital Currencies was established by the People's Bank of China to carry out research work on the creation of a state cryptocurrency. The need to create this scientific institution is associated with the desire to strengthen the country's financial position and stabilize the national currency. 
In September 2020, the five largest state-owned banks in China (Bank of China, Bank of Communications, Industrial and Commercial Bank of China, Agricultural Bank of China, Construction Bank of China), together with the China Banking Association, began to create and implement a blockchain system for organizing interbank money transfers for financing large government trade projects.

Banks participate in the development of the Digital Yuan project (DCEP), as well as in the implementation of blockchain technology in their activities (ICBC Bank, Ping An Bank, etc.). Some Chinese high-tech companies (Baidu, Huawei, Tencent, etc.) are also involved in the development of blockchain platforms. Implementation of the Digital Yuan program is a political project in China. The use of the digital yuan in international trade with 60 countries of the world is possible as a result of the implementation of the One Belt - One Road initiative, which may affect the reduction of the influence of the US dollar on the world stage.

The blockchain platform is also used by government agencies. In 2020, 140 digital areas of public services operated on it (for example, registration of real estate transactions, the provision of medical services, which was especially important in the context of a pandemic), which reduces costs and time for providing services to the population. Russian Vnesheconombank and China Development Bank are jointly investing 6 billion yuan in innovative blockchain and quantum technologies.

One of the most important problems in the implementation of blockchain technology in China is the lack of a single database since not all participants share their information. In addition, the blockchain system has a number of bottlenecks. Some blockchain technologies created by private companies are not immune to cyber threats. To solve these problems and expand the activities of blockchain platforms in various sectors of the economy in China in 2020, the National Blockchain Development Fund was created. It will help to finance the implementation of blockchain in Smart Government, and the industrial development of medium and small businesses.

In 2020, the Chinese government adopted the Beijing Blockchain Innovation Plan 20202022, the implementation of which will create a blockchain hub in Beijing. The blockchain hub will be used to integrate blockchain innovations into the infrastructure and economy of the city. In future, it is planned to create a Fund for Supporting Blockchain Startups.

The Russian Association for the Development of Financial Technologies unites 23 banks (Bank of Russia, Sber bank, VTB, Alfa-Bank, Gazprombank, Otkritie Bank, Bars Bank JSC, Bars Bank, RNCO center, Tinkoff Bank, Raiffeisen Bank, etc.), 2 payment system companies (National Payment Card System, the QIWI system), 5 insurance companies [6]. In Russia, on the basis of blockchain technology, a unified national system for the exchange and storage of financial information was created using an innovative platform for financial markets master chain [7]. This technology is designed to host such projects as a decentralized depository system for accounting for mortgages; the Know Your Customer project; a distribution register of digital bank guarantees; a digital letter of credit.

Many Russian banks and financial companies use blockchain technology in their activities. For example, Sber Factoring, together with M.Video, uses blockchain technology to eliminate errors and the human factor in factoring (for document verification). Alfa-Bank, together with S7 Airlines, organized the online sale of air tickets on the basis of the Ethereum platform. Yookassa program is technologically ready to work with bitcoin, as soon as this type of means of payment is allowed by the regulator. Sber is a member of the non-profit high-tech Enterprise Ethereum Alliance, which includes such well-known companies as Intel, JP Morgan, UBS, Microsoft, QIWI, etc. Due to the imposed sanctions, Sber was not included in the global banking blockchain consortium (R3). In 2017, Sber (as well as AlfaBank, MegaLabs MegaFon, IBM made a payment on a blockchain platform HyperLedger Fabric, which help to speed up the transaction of funds in real-time. 
Sber has established the Sber Blockchain Laboratory, which conducts research on innovative technologies on a blockchain platform, develops business directions in various sectors of the economy, creates product prototypes and implements pilot innovative projects, among which are the following: a) REPO transactions - a smart contract was created to speed up audit and data verification; b) mortgage bonds - were recorded in a decentralized depository network based on blockchain technology; c) factoring - decentralized control on the blockchain platform for factoring transactions; d) bank guarantees - carried out on the basis of a distributed data register.

Mining Solutions company from Novosibirsk has developed a software product that allows to increase the speed of calculations and reduce the amount of energy consumption of mining farms. In 2017, the company conducted ICO on the cryptocurrency market. In 2018, a miner was created to switch the system from one currency to another.

Blockchain platforms are being implemented not only in the financial field but also in other economic areas. For example, by Rentberry project, long-term rental housing operations are carried out; INS Ecosystem connects producers and consumers of food products; blockchain platform "Uservice" allows to register cars transactions.

The Russian Association of Cryptocurrencies and Blockchain, uniting miners and investors, could regulate cryptocurrencies in Russia. In November 2019, an agreement was reached between the Russian Association of Cryptocurrencies and Blockchain and the Chinese mining community Bit Main on further cooperation in the provision of capacities for mining data centers [8]. The use of blockchain technology will allow the BRICS countries to reduce the use of the US dollar and the services of intermediary banks in intra-group settlements.

In India, the BankChain financial blockchain consortium, uniting 27 public and private banks, develops and implements blockchain technology in the field of finance. The consortium has created blockchain applications in two beta versions - the use of smart contracts and "Know your customer", which are successfully used by 27 banks. Currently, the consortium is working on the implementation of innovative projects - the creation of a virtual currency, ensuring cross-border payments, and others.

The Indian government considers the use of blockchain technology in various sectors of the economy and cryptocurrency promising. Its "implementation has affected fields like ehealthcare, Internet of Things, smart contracts, e-finance, logistics, and so forth"[9]. A lot of work is being done in the country to integrate blockchain technology into the financial services and healthcare sectors. Blockchain platforms are widely used by Indian banks. Thus, ICICIC Bank carried out an international transaction using the blockchain system. And the Institute for Development and Research of Banking Technologies is working on the creation of a new blockchain platform "Distributed Center of Advanced Technologies in Blockchain". The duration of the project was two years (from March 2018 to March 2020), the amount of funding was 643 lakh rupees [10]. The implementation of the project will allow creating an ecosystem for the development of blockchain technology; design and use blockchain-based pilot projects in banking and finance; conduct research to solve problems associated with the use of the blockchain system in various fields.

In Brazil, based on blockchain technology, the central bank is working to create an alternative settlement system for transactions that can replace the main payment system during a financial collapse. The creation of an alternative settlement system can improve Brazil's financial infrastructure. In Brazil on the base of the blockchain platform, a citizen identification program was created, which was created by Microsoft and the ConsenSys blockchain startup. The Brazilian company BitVale has created a crypto machine that has been installed in Sao Paulo. Bitcoin is used in many Brazilian organizations as a means of payment, for example, at the Faculty of Informatics and Management, bitcoin is accepted as a tuition fee for courses in entrepreneurship, innovation, and project management. 
In South Africa, the widespread use of blockchain technology and cryptocurrency is being studied by the government. The Reserve Bank of South Africa and startup Benkimun are conducting a joint experiment to regulate bitcoin. Several banks and financial institutions have started developing blockchain technology platforms. For example, Absa Bank has joined an international blockchain consortium to organize this work. To introduce blockchain technology into the system of depositories, joint development is carried out by the Central Securities Depository of South Africa and the National Settlement Depository of the Russian Federation. South Africa launched an electronic voting system for shareholders at the Central Securities Depository on the base of the blockchain platform.

\subsection{Influence of robotization on the economic development of the country}

Innovations, robotics, artificial intelligence, have a profound impact on all areas of human life. Robotization is the highest innovative form of industrial automation. The introduction of robotization contributes to the development of the country's national innovation system.

China has achieved the greatest success in creating and manufacturing robots than the rest of the BRICS countries. Therefore, we will dwell in more detail on the development of robotization in China [11]. In 2016-2020, in accordance with the Robotics Industry Development Plan until 2020, China aimed to increase the production of industrial robots using Chinese technologies to 100 thousand [12]. A special role in the development of innovative products and technologies, including robotization, is assigned to an increase in funding for research and development. R\&D in China was $\$ 474.8$ billion. China is forecast to outstrip the United States in 2025-2026 in R\&D investment [13]. In 2018, sales of robots in China amounted to 154 thousand robots ( $\$ 5.4$ billion) [14]. Every third industrial robot in the world is sold in China. Most of the robots are being implemented in electronics $(50,000$ robots), automotive (43,000 robots) and metallurgy (20,000 robots). More than 800 high-tech Chinese companies have produced 72.4 thousand robots using innovative technologies such as big data, the Internet of things, cloud computing [14].

Chinese companies are working on the creation of their own production of robots, the prices of which are much lower than for similar imported goods. China is interested in setting up a production facility where robots will be produced by robots. With the help of the Swiss company, ABB in Shanghai in 2020 robots will be produced up to 100 thousand robots per year [15].

The operating stock of industrial robots in China increased 20.3 times over 2008-2018 to 649 thousand robots. To determine the impact of the development of robotics in China on GDP growth, correlation and regression analyzes were carried out, and a close relationship was revealed between the volume of the operating stock of industrial robots in China and the volume of its GDP for 2008-2018 (the correlation coefficient was 0.8909).

\section{Results. Development of digital transformation of the economy}

Blockchain can become an alternative to modern payment systems and technologies. In the financial sector, blockchain technology is being created to ensure the safe storage of funds. The blockchain base is decentralized, the cryptocurrency rate cannot be set by the Central Bank of the country.

In the course of the study, authors revealed the main advantages of creating and using a new cryptocurrency (for example, BRICScoin) and blockchain technology by BRICS countries: a) a unified digital currency of BRICS countries (BRICScoin) can become an alternative to the US dollar, which will create an opportunity to level the pressure of the US dollar on the development of the economies of BRICS countries [1]; b) there will be no need to use the US dollar as a reserve currency in gold and foreign exchange reserves; c) the terms 
and transaction costs of the economy will be reduced, there will be no need to use the services of intermediary banks for Intra-group settlements; d) cost optimization of state and corporate governance; e) protection of the financial system of BRICS countries from external threats, the absence of the possibility of a collapse of BRICScoin; f) growth of mutual investments of BRICS countries; g) increase in Intra-group trade cooperation; h) development of small and medium-sized businesses; i) decrease in inflation; j) cryptocurrency can be a major tool in the fight against financial sanctions; $k$ ) the growth of the economies of BRICS countries.

As a result of the regression analysis, the following regression equation was obtained: $Y=128168.34 \mathrm{x}_{1}+6310.81$

Based on the regression analysis, the following conclusion was made: an increase in the operating stock of industrial robots in China by 1 unit leads, on average, to an increase in China's GDP by $\$ 128,168.3$.

To determine the impact of R\&D funding on the development of robotics in China, a regression analysis was performed. As a result of the analysis, a very high correlation coefficient (0.9167) was determined, which made it possible to calculate the regression equation: $Y=1.5826 \mathrm{x}_{1}-250495.71357$

The following conclusion was made: an increase in the volume of R\&D expenditures by 1 thousand dollars leads, on average, to an increase in the volume of the operational stock of industrial robots in China by 1.6 units. The effect of $R \& D$ costs is very high since an increase in the volume of the operating stock of industrial robots in China by 1 unit leads on average to an increase in China's GDP by $\$ 128,168.3$.

The study of robotization in China made it possible to determine the advantages and disadvantages of this process. The main advantages of robotization in China are increased labor productivity; growth of the country's GDP, an increase in economic potential; optimization of the structure of the economy; modernization and automation of production; introduction of modern technologies and modern forms and methods of management; improving product quality and export competitiveness; development of research and development; reducing the volume of heavy unproductive labor; the introduction of robots in hazardous areas of production; improving the skills of the workforce, creating new highly qualified jobs.

The main problems of robotization in China are growing income inequality for Chinese citizens; loss of jobs and wages by the population; decrease in the volume of domestic consumption; growing shortage of highly qualified working-age population; aggravation of dependence on the growth of the Chinese economy on exports.

Solving these issues will increase labor productivity, the level of development of the country's economy, and the wellbeing of the people. The development of R\&D in China will contribute to the innovative development of the country's economy, an increase in the number of robots used in both production and service areas.

\section{Conclusions}

The analysis made it possible to determine recommendations for the development of digital cooperation between the BRICS countries.

The main threats to the use of blockchain and cryptocurrencies by countries are a) blockchain technology allows decentralizing the issuing center, Central banks cannot regulate the activities of cryptocurrency exchanges; $b$ ) the results of the movements of purchases and sales (transactions) on cryptocurrency exchanges cannot be tracked, and, therefore, it is impossible to tax them.

To develop the digital economy of BRICS countries and strengthen their integration, it is necessary: a) the development and implementation of a single cryptocurrency (for example, BRICScoin) for mutual settlements (instead of the US dollar); b) the creation of the Blockchain Fund for the development of payments in cryptocurrency between BRICS countries; c) binding 
the cryptocurrency of BRICS countries to the quotation of gold (not the US dollar) or to the derivative of the IMF SDR (Special Drawing Rights; d) introducing a blockchain system as an alternative to international money transfer systems (for example, SWIFT); e) expanding knowledge about the effectiveness of using blockchain technology in various sectors of the economy.

The study made it possible to identify the main directions for the further development of robotics in China: state support for innovative activities in the development of robotics through funding in the form of grants and placing government orders; development of publicprivate partnerships in robotics; creation of tax incentives for all enterprises (national and foreign) that produce robots and for enterprises that introduce robots into production in China; development of research work in the field of Big Data, Internet of Things, cloud computing, robotics; use of innovations and know-how of foreign companies that produce robots in China; holding competitions to identify the most effective innovative company in the field of robotics; government support for the patent activity of universities and research institutes.

\section{Acknowledgements}

This study was financed by a grant from the Plekhanov Russian University of Economics, Moscow, Russia \# 969 05.08.2020, \#1167 25.09.2020,\#1232 08.10.2020,\#1263 14.10.2020.

\section{References}

1. S.A. Gusarova, J. of Economy and entrepreneurship 11(10-2), (2017)

2. Sberbank http://www.caict.ac.cn/english/yjcg/bps/201901/P020190131402018699770.pdf

(2019).

3. J. Y. Lee, Business Horizons 62(6), 773 (2019). doi.org/10.1016/j.bushor.2019.08.003

4. Xinhuanet (2018). http://www.xinhuanet.com/english/2018-05/29/c_137213175_2.htm

5. Association for the Development of Financial Technologies (2019). https://fintechru.org/about/

6. Association for the Development of Financial Technologies (2020). https://fintechru.org/publications/sertifikatsiya-mastercheyna-dala-startpromyshlennoy-ekspluatatsii-blokcheyna-v-rossii/

7. Russian Association of Cryptocurrencies and Blockchain (2020). https://racib.com/rakib-provel-vstrechu-s-predstavitelyami-kitajskogo-majnerskogosoobshhestva

8. D. K. Sharma, S. Pant, M. Sharma, S. Brahmachari, Handbook of Research on Blockchain Technology, 323 (2020). https://doi.org/10.1016/B978-0-12-8198162.00013-7.

9. Institute for Development and Research in Banking Technology (2020), https://www.idrbt.ac.in/externalprojects.html

10. S. A. Gusarova, J. of Economy and entrepreneurship 6 (107), (2019).

11. CNYD (2017), http://en.cnydsci.com/html/news/meiti/122.html

12. Industrial Research Institute http://digital.rdmag.com/researchanddevelopment/2017_global_r_d_funding_forecast? pg=4\#pg 4 
13. International

Federation

of

Robotics

(2018),

https://ifr.org/downloads/press2018/IFR\%20World\%20Robotics\%20Presentation\%20$\% 2018 \% 20$ Sept\%202019.pdf

14. Mogg Trevor (2018). https://www.digitaltrends.com/cool-tech/robots-to-make-robotsat-one-of-the-worlds-most-advanced-facilities/ 